\title{
Increasing the bio-electrochemical system performance in azo dye wastewater treatment: Reduced electrode spacing for improved hydrodynamics
}

\author{
Hong-Cheng Wang ${ }^{\mathrm{a}, \mathrm{b}}$, Dan Cui ${ }^{\mathrm{c}}$, Li-Hui Yang ${ }^{\mathrm{a}, \mathrm{b}}$, Yang-Cheng Ding ${ }^{\mathrm{a}, \mathrm{b}}$, Hao-Yi Cheng ${ }^{\mathrm{a}}$, \\ Ai-Jie Wang, ${ }^{\mathrm{a}, \mathrm{d}, *}$ \\ ${ }^{a}$ Key Laboratory of Environmental Biotechnology, Research Center for Eco-Environmental Sciences, Chinese Academy of Sciences, Beijing 100085, PR China \\ b University of Chinese Academy of Sciences, Beijing 100049, PR China \\ c National Engineering Laboratory for Advanced Municipal Wastewater Treatment and Reuse Technology, Beijing University of Technology, Beijing 100124, China \\ d State Key Laboratory of Urban Water Resource and Environment, Harbin Institute of Technology (SKLUWRE, HIT), Harbin 150090, PR China
}

\section{G R A P H I C A L A B S T R A C T}

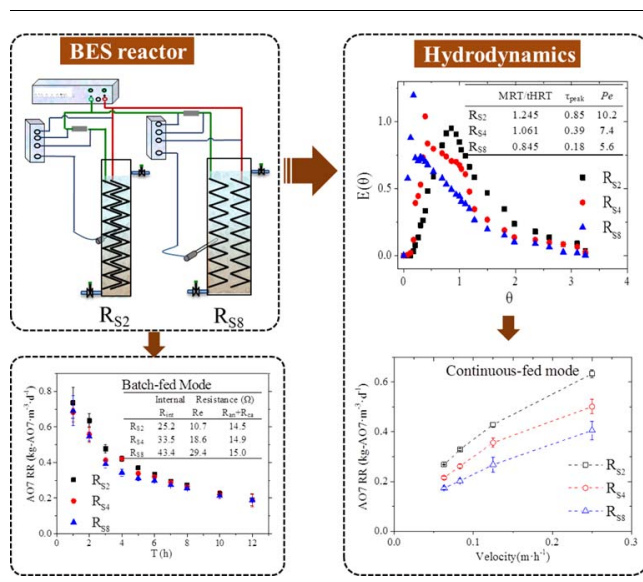

\section{A R T I C L E I N F O}

\section{Keywords:}

Azo dye

Bio-electrochemical systems

Electrode spacing

Hydrodynamic

Scaling-up

\begin{abstract}
A B S T R A C T
The electrodes spacing would exert a pronounced effect on bio-electrochemical systems (BESs) performance, especially for the scaling-up of reactors and practical applications. In this study, we traced the effect of electrode spacing on wastewater treatment performances from the aspects of hydrodynamics and electrochemical characteristics. Three series of folded stainless steel mesh ( $f$-SSM) electrodes with electrode spacing of 2, 4 and $8 \mathrm{~mm}$ were designed for azo dye (acid orange 7 (AO7)) wastewater treatment. Results showed that BES with electrode spacing of $2 \mathrm{~mm}\left(\mathrm{R}_{\mathrm{S} 2}\right)$ obtained the highest efficiencies of AO7 decolorization $(90.9 \pm 0.4 \%)$ and COD removal $(36.8 \pm 3.8 \%)$ at HRT of $8 \mathrm{~h}$, which was $30.7 \%$ and $15.2 \%$ higher than that in BES with electrode spacing of $8 \mathrm{~mm}\left(\mathrm{R}_{\mathrm{S} 8}\right)$, respectively. Moreover, the relationship between pollutants removal, internal resistance and hydrodynamics of BESs with different electrode spacing supported the hydrodynamics was significantly influence the pollutants removal performance.
\end{abstract}

\footnotetext{
* Corresponding author at: Key Laboratory of Environmental Biotechnology, Research Center for Eco-Environmental Sciences, Chinese Academy of Sciences, Beijing 100085, PR China. E-mail address: ajwang@rcees.ac.cn (A.-J. Wang).
} 


\section{Introduction}

As the most important industry in national economy in China, textile industry produced large quantities of azo dyes containing wastewater, which are toxic and highly persistent to biodegradation, raising attention for environmental concerns, as biological toxicity, "three-induced" (carcinogenicity, teratogenicity, mutagenicity) and undesirable aesthetic effects etc. (Pandey et al., 2007). Azo dyes are generally persistent under aerobic conditions but maybes reduced under anaerobic conditions, and anaerobic decolorization is a cost-efficient process; however, it is usually with slow rate and requires extra organic cosubstrate to provide electrons for the reduction(dos Santos et al., 2005). The co-substrate addition typically far exceeds the stoichiometric requirements, leading to additional costs and unwanted methane production (van der Zee and Villaverde, 2005). Thus, treatment process of azo dyes containing wastewater is a challenging issue that requires improvement. As all kinds of azo dye, acid orange 7 (AO7) is the most widely used dye in the textile industries, thus it is a significant component of wastewaters produced by these manufacturers that requires removal (Mu, 2009).

Recently, BESs have been explored extensively for its innovative features and environmental benefits for recalcitrant contaminants degradation in wastewater (Logan et al., 2006a,b; Rozendal et al., 2008), especially for azo dyes (Cui et al., 2016a; Mu, 2009; Sun et al., 2011), nitro-aromatics (Liang et al., 2014; Wang et al., 2011), and halogenated aromatics (Liang et al., 2013) reduction. However, most bio-electrochemical technologies developed until now have been restricted to lab scale as lacking of appropriate strategies to scaling-up. To overcome this challenge, numerous of researchers have focused on the BES scaling-up form many aspects, such as selection of suitable anode materials (Baudler et al., 2015; Guo et al., 2015; kumar et al., 2013; Zhou et al., 2011), improving catalyst activity in cathode (Heidrich et al., 2013; Zhang et al., 2014), as well as optimization of reactor architectures (Escapa et al., 2016), to name a few. Among these problems, electrode configuration and electrode spacing were of crucial importance and had attracted a great deal of attentions (Wei et al., 2011).

Different electrode spacing and configuration has significant impacts on internal resistance and thereby resulted in different power generation, COD removal and columbic efficiency (CE) (Ghangrekar and Shinde, 2007; Zhang et al., 2009). It is reported the maximum power output of air-cathode microbial fuel cells (MFCs) was increased $68 \%$, which corresponded to a decrease of internal resistance from 161 to $77 \Omega$ when the electrode spacing was reduced from 4 to $2 \mathrm{~cm}$ (Liu et al., 2005). The maximum power of MFC with continuous mode increased from $826 \mathrm{~mW} / \mathrm{m}^{2}$ to $1540 \mathrm{~mW} / \mathrm{m}^{2}$ as $75 \%$ overall decrease in internal resistance when the electrode spacing was decreased from 3 to $1 \mathrm{~cm}$ (Cheng et al., 2006). Besides, several studies demonstrated that the variation of electrode configurations has a strong relationship with hydrodynamics and takes an important role on mass transfer, convection and flow path of BESs. It demonstrated that MFC with full brush anodes spaced evenly between two cathodes (S2C) has slightly higher COD removal (6.4-24.4\%) and lower coulombic efficiency than the MFC with trimmed brush anodes near a single cathode (N1C). These results were attributed to the different hydrodynamics resulted by N1C configuration and S2C configuration, for example, at theoretical HRT of $8.8 \mathrm{~h}$, the measured HRT, dispersion number and Peclet number of the MFCs with N1C was $10.7 \mathrm{~h}, 0.020$ and 49, respectively, which were $7.4 \mathrm{~h}, 0.028$ and 36 for MFCs with S2C configuration, respectively (Kim et al., 2015). Therefore, the importance of internal resistance and hydrodynamics to performance becomes more important when design electrode spacing for BES in full-scale application. However, there was no studies consider both internal resistance and hydrodynamics impact on BES performance when varying the electrode spacing.

In this study, an innovative folded stainless steel mesh (f-SSM) electrode was developed (Wang et al., 2017) and built-in BES with different spacing $(2,4$ and $8 \mathrm{~mm}$ ) to treat azo dye wastewater. The performances of BESs from the aspects of hydrodynamics and internal resistance simultaneously investigated and carried out the research from three-folded. Firstly, three pairs of $f$-SSMs were deployed in three BESs with different electrode spacing. They were operated in batch-fed mode to investigate the relationship of electrode spacing and internal resistance of BESs and its effect on azo dye removal. Secondly, BESs were operated in continuous flow mode with four theoretical hydraulic retention times (HRTs) of $8,6,4$, and $2 \mathrm{~h}$. In addition, the hydrodynamic characteristics of BESs with different electrode spacing under different HRT conditions were investigated by tracer test and residence time distribution (RTD) curve. Finally, the relationship between hydrodynamics, internal resistance and pollutants removal performance were explored to reveal the significant effect of electrode spacing on BES performance.

\section{Materials and methods}

\subsection{BES construction}

Single-chamber BESs with up-flow channel were used in the present study. The electrode was made of SAE 304 stainless steel mesh with wire diameter of $0.18 \mathrm{~mm}$ and a filter rating of $20 \mathrm{~mm}$ (Kaian Ltd., China). The electrode was prepared as following: (1) cutting the single layer stainless steel mesh (SSM) into $7 \mathrm{~cm} \times 144 \mathrm{~cm}$ pieces (one side surface area of $0.1008 \mathrm{~m}^{2}$ ); (2) folding the single layer SSM pieces according to Zheng and colleagues' method (Zheng et al., 2015) to maintain folding angle with $40^{\circ}$; (3) the folded SSM electrode was thoroughly treated in $1 \mathrm{M} \mathrm{H}_{2} \mathrm{SO}_{4}$ for $24 \mathrm{~h}$ to remove surface oxides and obtain a rough surface; (4) cleaning SSM by deionized water and drying in air. Titanium wire $(\varphi 1 \mathrm{~mm})$ was used as the current collector, copper wire was used to connect the electrodes to an external resistor $\left(\mathrm{R}_{\mathrm{ex}}=10 \Omega\right)$.

The spacing of anode and cathode in the plexiglas reactor was varied in order to systematically investigate the effect of electrode spacing on BES performance. The electrode spacing, $D$, defined as the vertical distance between anode and cathode, was set as 2, 4 and $8 \mathrm{~mm}$ (Fig. 1). The BES with electrode spacing of 2,4 and $8 \mathrm{~mm}$, was denoted as $R_{S 2}, R_{S 4}$ and $R_{S 8}$, respectively. Correspondingly, the effective reactor volumes were $1.55,1.85$ and $2.25 \mathrm{~L}$. The specific surface areas of the cathode electrode per volume of reactor were 65, 55, and $45 \mathrm{~m}^{2} \mathrm{SSM} \mathrm{m}{ }^{-3}$, respectively. The $f$-SSM electrodes were all placed close to the wall of reactor to make sure all of wastewater penetrated the electrode. $\mathrm{An} \mathrm{Ag} / \mathrm{AgCl}$ reference electrode $(+197 \mathrm{mV}$ vs standard hydrogen electrode) (Shanghai Precision Scientific Instruments Co., Ltd., China) was installed between the anode and the cathode to enable potential measurement. Electric power $(0.5 \mathrm{~V})$ was provided to each pair of electrode with a power supply (PS-3005D, Zhaoxin Co., Ltd., China) during the whole experiments. The voltage across external resistor, cathode potential and anode potential were recorded using the data acquisition system (Keithley 2700, Keithley Co., Ltd., USA) every $10 \mathrm{~min}$.

\subsection{Operating conditions}

\subsubsection{Inoculation and start-up}

Three BESs $\left(R_{S 2}, R_{S 4}\right.$ and $\left.R_{S 8}\right)$ were all inoculated with $10 \mathrm{~mL}$ of concentrated anaerobic sludge from a laboratory-scale biocatalyzed electrolysis system that had been operated for about 200 days, with mixed liquor suspended solid (MLSS) concentration of $7 \mathrm{~g} \mathrm{~L}^{-1}$. During the start-up period, the reactors were continuously fed domestic wastewater containing $100 \mathrm{mg} \mathrm{L}^{-1} \mathrm{AO}$, the theoretical HRT was fixed at $8 \mathrm{~h}$ by a peristaltic pump (Longer Co., China). Current output was observed in all reactors after 2 days and finally reached plateau after a rising duration. 


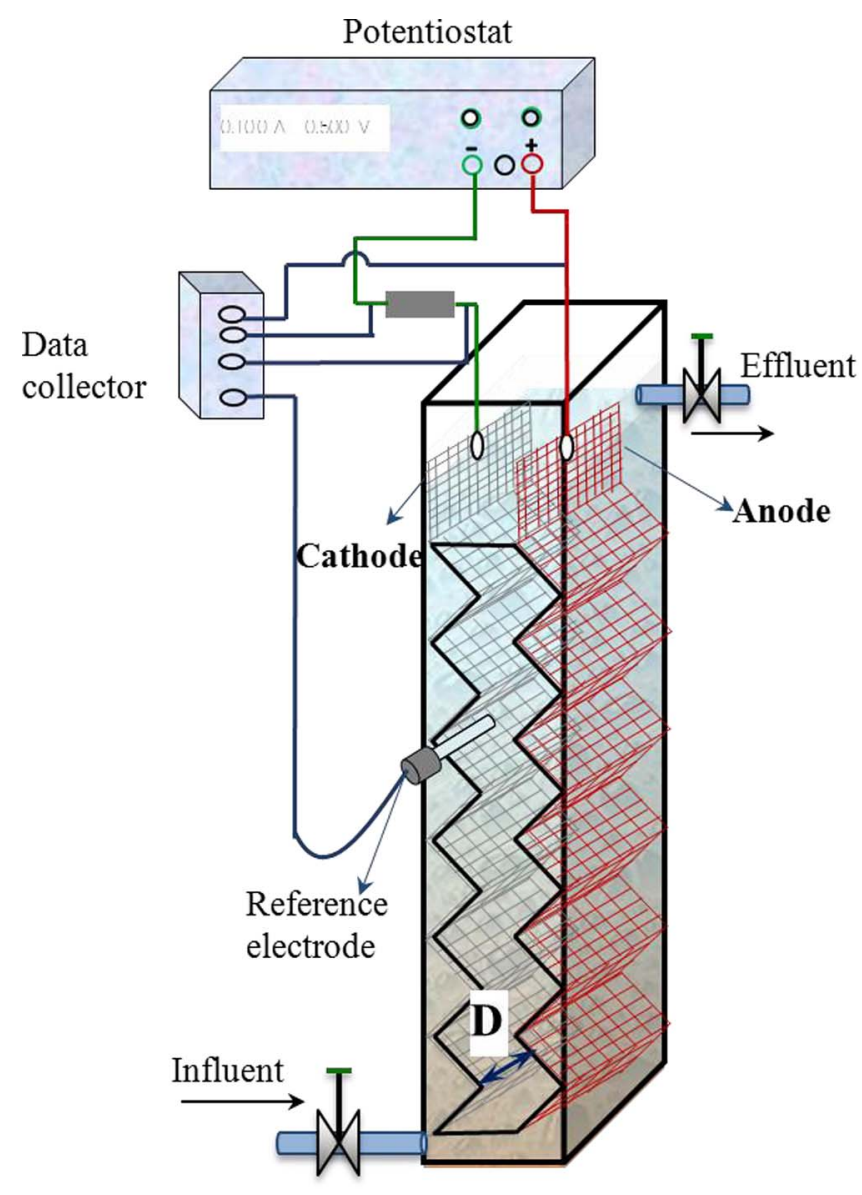

Fig. 1. Schematic diagram of BES with $f$-SSM electrode.

\subsubsection{Batch-fed and continuous flow modes}

After start-up successfully, the three BESs were conducted in batchfed mode for 10 days with initial AO7 concentration of $100 \mathrm{mg} \mathrm{L}^{-1}$ for 5 cycles. Then, the operation was switched to continuous flow mode lasting for more than 110 days. Three BESs were continuously fed with domestic wastewater (average COD of $518 \pm 56 \mathrm{mg} \mathrm{L}^{-1}$ ) containing $100 \mathrm{mg} \mathrm{L}^{-1}$ AO7. Four different theoretical hydraulic retention times (2, 4, 6 and $8 \mathrm{~h}$ ) were investigated by varying the flow rates. Each loading rate was repeated at least 100 times, with all data reported as the average of replicate experiments. All of the experiments mentioned were conducted at ambient temperature $\left(24-29^{\circ} \mathrm{C}\right)$.

\subsubsection{Hydrodynamic test}

RTD analysis was conducted according to the stimulus-response method by using AO7 as tracer as it was easy determined and represented the actual flow regime of BES reactor. The theoretical HRT was calculated from the set flow rate $\left(Q, \mathrm{~mL} \mathrm{~h}^{-1}\right)$ and reactor volume $(\mathrm{V}, \mathrm{mL})$ as $\mathrm{HRT}=V / \mathrm{Q}$. Different flow rates were chosen to obtain the same theoretical HRTs $(8,6,4$ and $2 \mathrm{~h})$ for the three reactors. Tracer test was conducted to measure the actual residence time of solutes in the three BESs during continuous mode operation according to Nwabueze (Nwabueze and Iwe, 2008). The mean residence time (MRT) was used to characterize the measured HRT (mHRT), and square of the standard deviation $\left(\sigma_{\theta}^{2}=1 / \mathrm{N}\right)$ was used to characterize the degree of back-mixing in different reactors. Peclet number (Pe) was obtained from the normalized variance of the tracer curve to characterize the mass transport.

\subsection{Analysis and calculations}

Liquid samples taken from the BESs were filtered through $0.45 \mu \mathrm{m}$ membrane filters. COD was measured by a COD analyzer (HACH DRB200 and DR3900, USA). The AO7 concentration was determined by UV-Vis spectrophotometer (HACH DR3900, USA) at the wavelength of $484 \mathrm{~nm}$ (Mu, 2009). The current (mA) was obtained based on the detected voltage across the sampling resistor according to the Ohm's law.

The pollutant removal efficiency (RE, \%) and removal rate (RR, kgAO7 $\mathrm{m}^{-3} \mathrm{~d}^{-1}$ or $\mathrm{kg}$-COD m $\mathrm{m}^{-3} \mathrm{~d}^{-1}$ ) were calculated according to the previous study (Cui et al., 2014) .The coulombic efficiencies (CE) for AO7 and COD were evaluated according to Logan et al. (2006a,b).

$$
\begin{aligned}
& C E_{A O 7-\text { batch }}=\frac{\sum_{i=0}^{n} I\left(t_{i}\right) \Delta t_{i}}{4 \times \frac{\left(C_{A O 7}\left(t_{0}\right)-C_{A O 7}\left(t_{n}\right)\right)}{M_{A O 7}} \times V \times F} \times 100 \% \\
& C E_{C O D-\text { batch }}=\frac{\sum_{i=0}^{n} I\left(t_{i}\right) \Delta t_{i}}{4 \times \frac{\left(C_{C O D}\left(t_{0}\right)-C_{C O D}\left(t_{n}\right)\right)}{M_{C O D}} \times V \times F} \times 100 \% \\
& C E_{C O D-\text { continuous }}=\frac{I}{4 \times \frac{\left(C_{\text {in-COD } \left.-C_{\text {eff-COD }}\right)}\right.}{M_{C O D}} \times \frac{Q \times 10^{3}}{24 \times 3600} \times F} \times 100 \% \\
& C E_{A O 7-\text { continuous }}=\frac{I}{4 \times \frac{\left(C_{\left.i n-A O 7-C_{e f f-A O 7)}\right)}\right.}{M_{A O O}} \times \frac{Q \times 10^{3}}{24 \times 3600} \times 10^{3} \times F} \times 100 \%
\end{aligned}
$$

where, $\mathrm{C}_{\mathrm{AO} 7}\left(\mathrm{t}_{0}\right)$ and $\mathrm{C}_{\mathrm{AO} 7}\left(\mathrm{t}_{\mathrm{n}}\right)$ were the initial and final $\left(\mathrm{t}_{\mathrm{n}}=12 \mathrm{~h}\right) \mathrm{AO} 7$ concentration for the batch test $\left(\mathrm{mg} \mathrm{L}^{-1}\right)$. $\mathrm{C}_{\mathrm{COD}}\left(\mathrm{t}_{0}\right)$ and $\mathrm{C}_{\mathrm{COD}}\left(\mathrm{t}_{\mathrm{n}}\right)$ were the initial and final $\left(t_{n}=12 \mathrm{~h}\right)$ COD concentration for the batch test ( $\mathrm{mg} \mathrm{L}^{-1}$ ). $\Delta t i$ was the time interval for current acquisition (s), $M_{\mathrm{AO} 7}$ and $M_{\text {COD }}$ were the molecular weight of AO7 and oxygen $\left(\mathrm{g} \mathrm{mol}^{-1}\right), V$ was the volume of BESs $\left(\mathrm{m}^{-3}\right), \quad F$ was Faraday's constant (96485 $\mathrm{C} \mathrm{mol}^{-1} \mathrm{e}$ ), 4 was the number of electrons exchanged per mole of $\mathrm{AO} 7$ or oxygen, $\mathrm{C}_{\mathrm{in}-\mathrm{AO} 7}$ and $\mathrm{C}_{\text {eff-AO7 }}$ were influent and effluent $\mathrm{AO} 7$

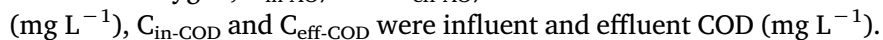

To estimate the internal resistances of BESs, $R_{\text {int }}$ was measured by using the linear portion of the polarization curve obtained using linear sweep voltages (LSV) with the anode as the working electrode, cathode as counter electrode and reference electrode (Ahn and Logan, 2013, 2012; Escapa et al., 2015; Logan, 2008). In the single-chamber BES as described in this research, the total internal resistance $R_{\text {int }}$ can be dissected into anodic resistance $R_{\mathrm{an}}$, cathodic resistance $R_{\text {ca }}$, contact resistance $R_{\text {co }}$, and electrolyte resistance $R_{\mathrm{e}}$ (Cheng et al., 2006; Fan et al., 2008).

\section{Results and discussion}

\subsection{Influence of internal resistance on BES performance}

LSV (Logan, 2008) was conducted to measure the internal resistances of the three BESs with different electrode spacing. As shown in Table 1, larger electrode spacing resulted in higher internal resistances. The total internal resistances of $R_{S 2}, R_{S 4}$ and $R_{S 8}$ measured via LSV were $26.2,33.5$ and $43.4 \Omega$, respectively. The difference in internal resistance can be contributed to the electrolyte resistances (Re), as Re showed increased with the increasing of electrode spacing and were 10.7, 18.6 and $29.4 \Omega$ for $R_{S 2}, R_{S 4}$ and $R_{S 8}$ in order. Thus, we believed that electrode spacing took an important role on ion transfer and led to different electrolyte resistances.

To value the impact of electrolyte resistance on AO7 and COD removal in BESs, the BESs were operated in batch-fed mode. As Fig. 2 shown, AO7 and COD removal efficiencies were close in the three reactors. In terms of kinetics, the AO7 removal fitted first-order kinetic model very well $\left(\mathrm{R}^{2}>0.97\right), \mathrm{R}_{\mathrm{S} 4}$ observed the highest rate constant $k$ of $0.264 \mathrm{~h}^{-1}$, followed by $R_{S 2}\left(0.258 \mathrm{~h}^{-1}\right)$ and $R_{S 4}\left(0.230 \mathrm{~h}^{-1}\right)$ 
Table 1

Comparison of internal resistance and bio-electrochemical characteristics of BESs with different electrode spacing.

\begin{tabular}{|c|c|c|c|c|c|c|c|c|}
\hline \multirow[t]{2}{*}{ Reactor } & \multicolumn{3}{|c|}{ Internal resistance $(\Omega)$} & \multirow[t]{2}{*}{$Q_{\mathrm{I}}(\mathrm{C})$} & \multirow[t]{2}{*}{$Q_{\text {AO7-batch }}(\mathrm{C})$} & \multirow[t]{2}{*}{$Q_{\text {COD-batch }}(\mathrm{C})$} & \multirow[t]{2}{*}{$\mathrm{CE}_{\mathrm{AO} 7-\text { batch }}(\%)$} & \multirow[t]{2}{*}{$\mathrm{CE}_{\text {COD-batch }}(\%)$} \\
\hline & $\mathrm{R}_{\text {int }}$ & $\mathrm{R}_{\mathrm{e}}$ & $\mathrm{R}_{\mathrm{an}}+\mathrm{R}_{\mathrm{ca}}$ & & & & & \\
\hline $\mathrm{R}_{\mathrm{S} 2}$ & 25.2 & 10.7 & 14.5 & $185.3 \pm 5.9$ & $161.6 \pm 8.6$ & $4043.5 \pm 245.6$ & $114.7 \pm 6.8$ & $4.6 \pm 0.3$ \\
\hline $\mathrm{R}_{\mathrm{S} 4}$ & 33.5 & 18.6 & 14.9 & $221.6 \pm 8.7$ & $192.5 \pm 6.1$ & $5144.6 \pm 457.1$ & $115.1 \pm 7.4$ & $4.3 \pm 0.2$ \\
\hline $\mathrm{R}_{\mathrm{S} 8}$ & 43.4 & 29.4 & 15.0 & $254.0 \pm 7.9$ & $234.1 \pm 6.8$ & $5552.3 \pm 398.1$ & $108.5 \pm 5.6$ & $4.6 \pm 0.7$ \\
\hline
\end{tabular}

$Q_{I}$ : electric quantity calculated based on the measured current $\left(t_{\mathrm{n}}=12 \mathrm{~h}\right)$.

$Q_{A O 7}$ : theoretical electric quantity calculated based on the AO7 removal $\left(t_{\mathrm{n}}=12 \mathrm{~h}\right)$.

$Q_{C O D}$ : theoretical electric quantity calculated based on the COD removal $\left(t_{\mathrm{n}}=12 \mathrm{~h}\right)$.

(Fig. 2a). Correspondingly, the AO7 removal efficiencies at $12 \mathrm{~h}$ reached $94.8 \pm 1.2 \%, 95.8 \pm 0.9 \%$ and $94.7 \pm 1.5 \%$ in $R_{S 2}, R_{S 4}$ and $\mathrm{R}_{\mathrm{S} 8}$, respectively. The COD removal showed the same trend (Fig. 2b) with the similarly COD removal efficiency of $40 \%$ in all reactors. Moreover, the columbic efficiencies (CEs) based on COD removal and current generation were calculated to further investigate the performance of bioelectrochemical process that took place in the reactors. CEs based on COD removal ( $\mathrm{CE}_{\mathrm{COD} \text {-batch }}$ ) ranged from $4.31 \pm 0.07 \%\left(\mathrm{R}_{\mathrm{S} 4}\right)$ to $4.58 \pm 0.26 \%\left(R_{S 2}\right)$ indicating the organics was sufficient for anodic microbial respiring and growth. $Q_{\mathrm{I}}$ (electric quantity calculated based on the measured current within $12 \mathrm{~h}$ operation time) of $\mathrm{R}_{\mathrm{S} 2}, \mathrm{R}_{\mathrm{S} 4}$ and $\mathrm{R}_{\mathrm{S} 8}$ were $185.3 \pm 5.9,221.6 \pm 8.7$ and $254.0 \pm 7.9$ Coulomb, with corresponding $\mathrm{CE}_{\mathrm{AO} 7}$ of $114.7 \pm 6.8 \%, \quad 115.1 \pm 7.4 \%$ and $108.5 \pm 5.6 \%$, respectively. $\mathrm{CE}_{\mathrm{AO} 7}$ in all BESs were slightly higher than $100 \%$, suggesting that electrons transferred from the anode to the cathode were sufficient for AO7 reduction in the three BESs. The above results implied that although the electrode spacing varying between 2 and $8 \mathrm{~mm}$ led to electrolyte resistances increasing from $10.7 \Omega$ to
$29.4 \Omega$, it did not affect the wastewater treatment performance obviously with power and enough carbon sources apply.

\subsection{Hydrodynamics characteristics}

The hydrodynamics of BESs with different electrode spacing were compared via tracer test and residence time distribution (RTD) curve analysis. The RTD curves showed the overall hydrodynamics behavior for each theoretical HRT $\left(\mathrm{HRT}_{\mathrm{t}}\right)$. As shown in Fig. 3, only one peak was observed for each RTD curve, which indicated that all the BESs reactors were operated without obviously inner circulation and preferential flow (Kjellstrand et al., 2005; Wang et al., 2015). The RTD curve obtained for $\mathrm{R}_{\mathrm{S} 2}$ showed a typical plug flow-like curve (with RTD peaks about 0.9 $\theta$ ). However, it presented a typical shape of a poorly mixed reactor with dead volumes for $R_{S 8}$, as much earlier presence of RTD peaks (about $0.25 \theta$ ). The RTD peaks of $\mathrm{Rs}_{2}$ observed between $0.81 \theta$ and $1.05 \theta$, indicating the real HRT of $\mathrm{Rs}_{2}$ was much close to theoretical HRT. Thus, it seemed that minifying electrode spacing in BESs could improve the
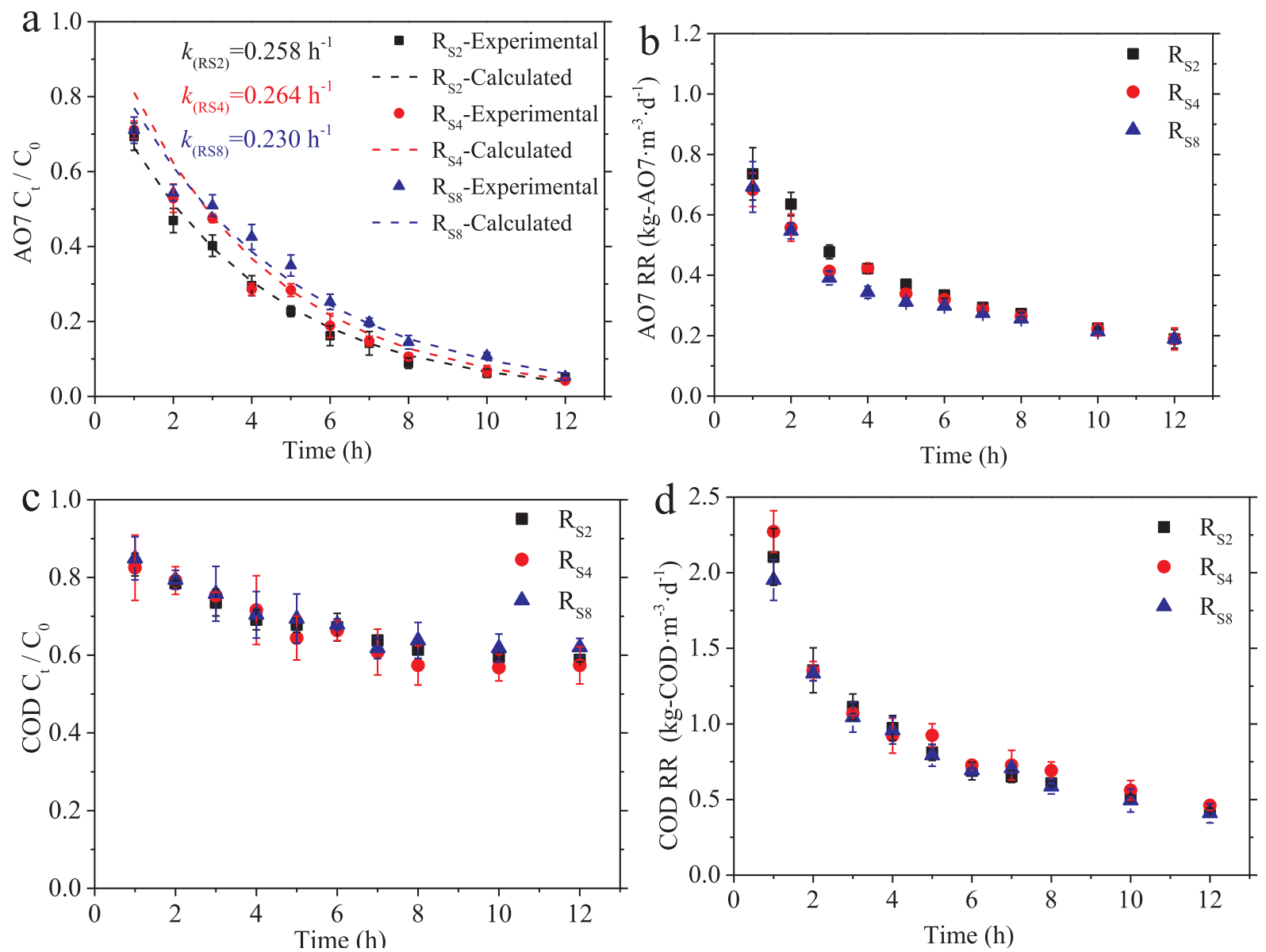

Fig. 2. Comparison of (a) AO7 removal, (b) AO7 removal rate, (c) COD removal and (d) COD removal rate in different reactors with batch-fed mode. 


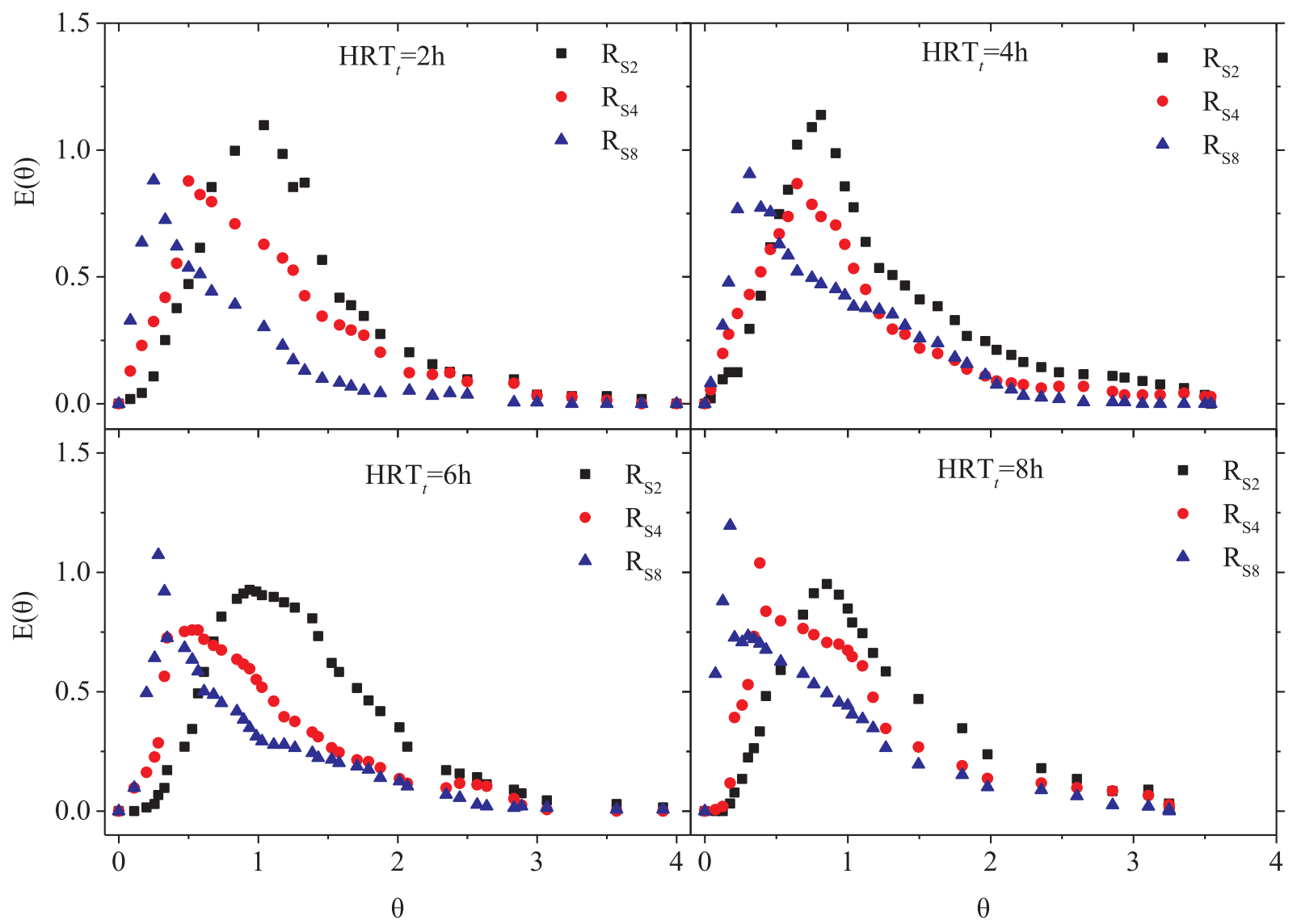

Fig. 3. Different BES reactors RTD curves with four different HRTt (2, 4, 6 and 8h).

hydrodynamics in the reactors.

In addition, the RTD curves can be mathematically featured by two key parameters, the retention time factors $(\beta)$ and the Peclet number $(P e)$, which were listed in the Table 2. The retention time factors $(\beta)$ were used to show the ratio between MRT and theoretical HRT. The $\beta$ values of each reactor at outlet and the internal points showed the same trend at different tHRTs. The largest $\beta(1.27 \pm 0.05)$ was observed at $R_{S 2}$, and the value declined linearly with increasing of electrode

Table 2

Hydrodynamic parameters of BES with different electrode spacing.

\begin{tabular}{lllllllll}
\hline HRT $_{\mathrm{t}}{ }^{\mathrm{a}}$ & & $\mathrm{MRT}^{\mathrm{b}}$ & $\beta^{\mathrm{c}}$ & $\varepsilon(\%)^{\mathrm{d}}$ & $\tau_{\text {peak }}{ }^{\mathrm{e}}$ & $\mathrm{N}^{\mathrm{f}}$ & $P^{\mathrm{g}}$ & $\delta_{\theta}^{2 \mathrm{~h}}$ \\
\hline \multirow{2}{*}{2} & $\mathrm{R}_{\mathrm{S} 2}$ & 2.47 & 1.234 & 100.4 & 1.05 & 3.9 & 10.7 & 0.256 \\
& $\mathrm{R}_{\mathrm{S} 4}$ & 2.19 & 1.097 & 94.7 & 0.51 & 2.7 & 8.1 & 0.372 \\
& $\mathrm{R}_{\mathrm{S} 8}$ & 1.43 & 0.716 & 81.3 & 0.25 & 1.7 & 6.0 & 0.582 \\
4 & $\mathrm{R}_{\mathrm{S} 2}$ & 4.96 & 1.240 & 100.1 & 0.81 & 3.7 & 10.5 & 0.270 \\
& $\mathrm{R}_{\mathrm{S} 4}$ & 4.41 & 1.103 & 86.7 & 0.65 & 2.7 & 8.0 & 0.364 \\
& $\mathrm{R}_{\mathrm{S} 8}$ & 3.40 & 0.850 & 78.6 & 0.31 & 2.4 & 7.3 & 0.421 \\
& & & & & & & & \\
& $\mathrm{R}_{\mathrm{S} 2}$ & 8.17 & 1.316 & 93.1 & 0.89 & 4.5 & 12.1 & 0.220 \\
& $\mathrm{R}_{\mathrm{S} 4}$ & 6.32 & 1.053 & 86.1 & 0.53 & 2.7 & 8.2 & 0.365 \\
& $\mathrm{R}_{\mathrm{S} 8}$ & 5.59 & 0.931 & 82.8 & 0.28 & 2.0 & 6.4 & 0.501 \\
& $\mathrm{R}_{\mathrm{S} 2}$ & 10.03 & 1.245 & 92.9 & 0.85 & 3.7 & 10.2 & 0.272 \\
& $\mathrm{R}_{\mathrm{S} 4}$ & 8.49 & 1.061 & 96.4 & 0.39 & 2.4 & 7.4 & 0.415 \\
& $\mathrm{R}_{\mathrm{S} 8}$ & 6.76 & 0.845 & 80.2 & 0.18 & 1.6 & 5.6 & 0.608 \\
& & & & & & & &
\end{tabular}

a Theoretical hydraulic retention time.

b Mean residence time.

c $\mathrm{MRT} / \mathrm{HRT}_{\mathrm{t}}$

d Tracer recovery.

e The normalized time of the E-curve peak.

${ }^{f}$ CSTR number calculated by TIS model.

${ }^{g}$ Peclet number.

h Variances of RTD curve. spacing. The smallest values of $\beta(0.84 \pm 0.08)$ for the $R_{S 8}$ showed coexisting short-circuiting fractions plus dead zones (i.e., stagnant volumes) for these runs. This was confirmed by the lower tracer recovery average with $80.7 \pm 1.5 \%$ and earlier peak time about 0.250 . Additionally, the $\beta$ values in $R_{S 2}$ and $R_{S 4}$ even over one, this was probably due to some eddies formed as a portion of fluid blocked by stainless steel wire, which changed the flow regime and extend the fluid path in the reactors (Rhines and Holland, 1979; Nere et al., 2003; Travin et al., 2002). Similar results were also reported in the bioelectrochemical system with carbon brush electrode (Kim et al., 2015) or other bioreactors equipped with different carriers (Munoz et al., 2006; Rebecca Moore, 2001). Besides, the smaller electrode spacing, the larger Pe values can be observed (Table 2), indicating that mass transfer in the reactors were mainly driven by convection but not by diffusion. The $P e$ values of $\mathrm{R}_{\mathrm{S} 2}$ for most $\mathrm{HRT}_{\mathrm{t}}$ were higher than 10, indicating no substantial differences in the effect of plug flow reactor (PFR). However, the overall hydrodynamic pattern of $\mathrm{R}_{\mathrm{S} 4}$ and $\mathrm{R}_{\mathrm{S} 8}$ converged to CSTR model as the Pe values ranging from 5.6 to 8.2.

As discussed above, reducing electrode spacing in BES could improve the hydrodynamic behavior, such as minimize dead zone and short-circuiting, prolong mean residence time and promote the transverse convection mass transfer. There are several possible reasons for the variations of BES hydrodynamic when varied the electrode spacing. Firstly, electrode with smaller electrode spacing represents larger electrode surface area/volume. For example, electrode surface area/ volume in $\mathrm{R}_{\mathrm{S} 2}$ was $64.8 \mathrm{~m}^{2} \mathrm{SSM} \mathrm{m}^{-3}$, which was 1.19 $\left(54.3 \mathrm{~m}^{2} \mathrm{SSM} \mathrm{m}{ }^{-3}\right)$ and $1.45\left(44.7 \mathrm{~m}^{2} \mathrm{SSM} \mathrm{m}{ }^{-3}\right)$ times of $\mathrm{R}_{\mathrm{S} 4}$ and $\mathrm{R}_{\mathrm{S} 8}$, respectively. Surprisingly, we found that retention time factors $\beta$ of $R_{S 2}$ was 1.18 and 1.52 times of $R_{S 4}$ and $R_{S 8}$, which were almost the same as the electrode surface area/volume, suggesting that electrode surface area/volume of BESs had a direct impact on the reactor hydrodynamics behavior. Secondly, the $f$-SSM electrode with smaller electrode spacing 

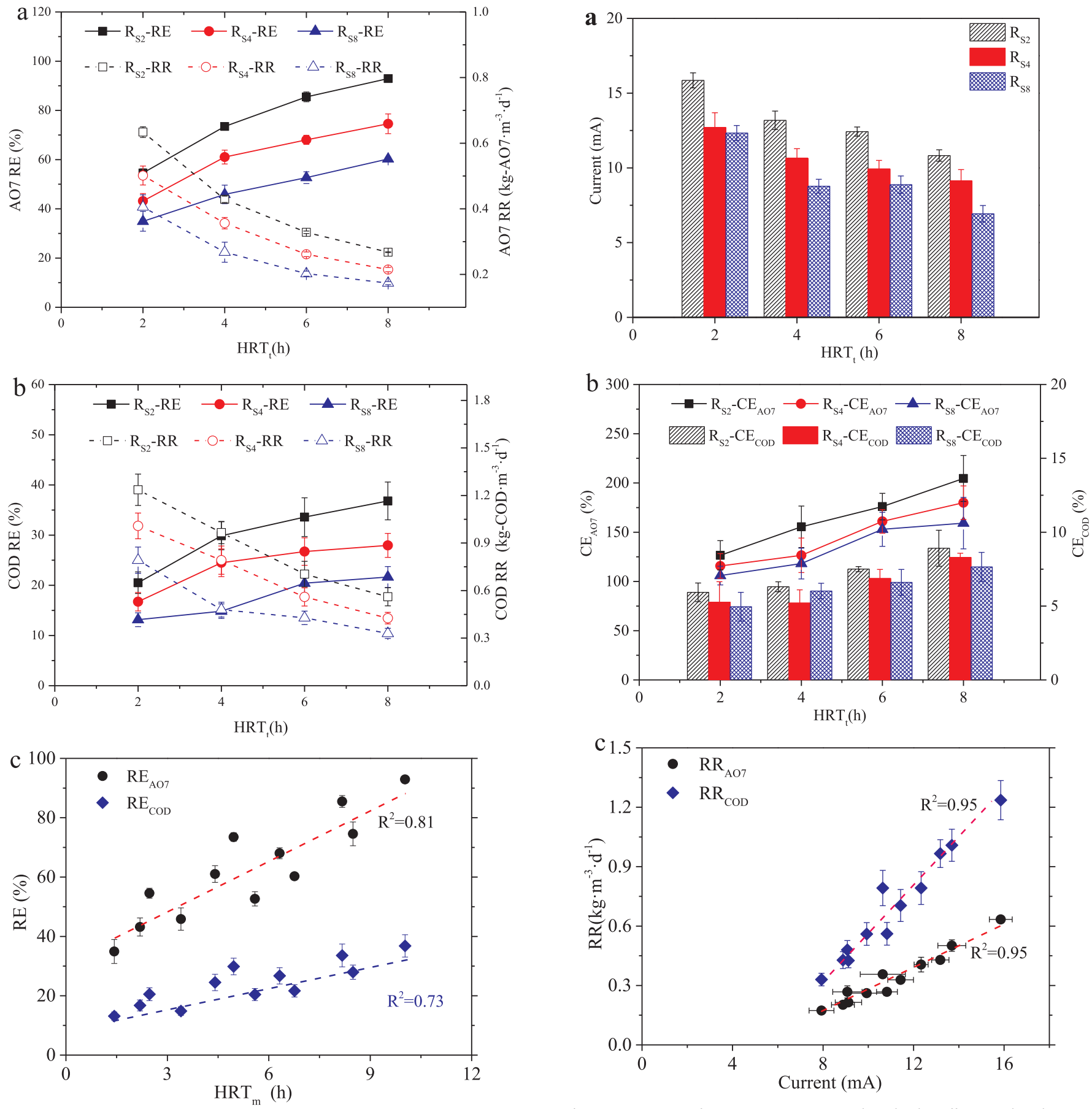

Fig. 4. Comparison of (a) AO7, (b) COD removal in different reactors with continuous flow, (c) Pollutants removal efficiency of BES with different electrode spacing based on measured HRTs.

can form more complicated geometric convex in macro-meter scale, which could greatly influenced the flow channel, enhanced mixing and hence increases the macroscale mass transfer rates, which could greatly enhance the mobility of reactants and subsequently improve the reaction efficiency (Ji et al., 2015).

\subsection{Influence of hydrodynamics characteristics on BES performance}

\subsubsection{AO7 and COD removal}

As Fig. 4 shown, under continuous flow operational condition, both AO7 and COD removal efficiencies and removal rates dramatically increased with the decreasing of electrode spacing, and thus $\mathrm{R}_{\mathrm{S} 2}$ with the

Fig. 5. Comparison of (a) current generation, (b) columbic efficiency (based on AO7 decolorization and COD removal) in different reactors with continuous flow, (c) Pollutants removal rates of BES with different electrode spacing based on current generation.

closest spacing exhibited the best performance. The AO7 removal efficiency in $\mathrm{R}_{\mathrm{S} 2}$ grew from $54.6 \pm 1.7 \%$ to $90.9 \pm 0.4 \%$ when $\mathrm{HRT}_{\mathrm{t}}$ extended from $2 \mathrm{~h}$ to $8 \mathrm{~h}$, which was $14.4 \%$ and $27.7 \%$ in average higher than that in $\mathrm{R}_{\mathrm{S} 4}$ and $\mathrm{R}_{\mathrm{S} 8}$, respectively. The highest AO7 removal rate $(\mathrm{AO} 7 \mathrm{RR})$ in $\mathrm{R}_{\mathrm{S} 2}$ reached $0.634 \pm 0.016 \mathrm{~kg}-\mathrm{AO} 7 \mathrm{~m}^{-3} \mathrm{~d}^{-1}$ at $\mathrm{HRT}_{\mathrm{t}}$ of $2 \mathrm{~h}$, which was $56.3 \%$ higher than that in $\mathrm{R}_{\mathrm{S} 8}$.

COD removals showed the similar trend as the AO7 in the three BESs. The highest COD removal efficiency $(36.8 \pm 3.8 \%)$ was obtained in $R_{S 2}$ at HRTt of $8 \mathrm{~h}$ (organic loading rate $=1.52 \pm 0.14 \mathrm{~kg}$ $\operatorname{COD~m}{ }^{-3} \mathrm{~d}^{-1}$ ), which were $8.8-15.1 \%$ higher than those in $\mathrm{R}_{\mathrm{S} 4}$ and $\mathrm{R}_{\mathrm{S} 8}$. Although this value declined to $20.5 \pm 2.2 \%$ in $\mathrm{R}_{\mathrm{S} 2}$ at the shortest HRTt $\left(\mathrm{HRT}_{\mathrm{t}}=2 \mathrm{~h}\right.$, organic loading rate of $6.09 \pm 0.59 \mathrm{~kg}$ - 
Table 3

Basic assumptions in the techno-economic assessment.

\begin{tabular}{|c|c|c|c|}
\hline Parameters & Concept & Unit & Calculation equations/Values \\
\hline$C_{\mathrm{IC}}$ & Initial capital cost of BES & $€ \mathrm{~kg}-\mathrm{AO}^{-1} \mathrm{~d}^{-1}$ & $C_{\mathrm{IC}}=\left(U_{r e}+U_{\text {oth }}+U_{\text {ele }}\right) / f(x)$ \\
\hline$x$ & AO7 removal efficiency & $\%$ & \\
\hline \multirow[t]{3}{*}{$f(x)$} & Function between AO7 vLRs and $\mathrm{RE}_{\mathrm{AO} 7}$ & & $\left(8.223 e^{-0.036 x} R^{2}=1.000 R_{S 2}\right.$ \\
\hline & & & $f(x)=\left\{8.017 e^{-0.036 x} \quad R^{2}=0.994 \quad R_{S 4 x} \in[34.9,92.9]\right.$ \\
\hline & & & $7.734 e^{-0.036 x} \quad R^{2}=0.989 \quad R_{S 8}$ \\
\hline$U_{\mathrm{re}}$ & Unit cost of reactor & $€ \mathrm{~m}^{-3} \mathrm{NV}$ & $94.32^{\mathrm{a}}$ \\
\hline$U_{\text {oth }}$ & Other cost of a unit electrode module $\left(1 \mathrm{~m}^{3}\right)$ & $€ \mathrm{~m}^{-3} \mathrm{NV}$ & $14.51^{\mathrm{b}}$ \\
\hline$U_{\text {SSM }}$ & Cost of SSM of an unit electrode module $\left(1 \mathrm{~m}^{3}\right)$ & $€$ module ${ }^{-1}$ & $U_{\text {ele }}=A_{\mathrm{SSM}} \cdot U A_{\mathrm{SSM}}$ \\
\hline$A_{\text {SSM }}$ & Area of SSM of an unit electrode module & $\mathrm{m}^{2} \mathrm{SSM} \cdot \mathrm{module} \mathrm{e}^{-1}$ & $A_{S S M}=0.06 \cdot\lfloor 50 \csc (40 \pi / 360) / 3\rfloor \cdot\lfloor 1000 /(d \csc (40 \pi / 360)+30 \cos (40 \pi / 360)\rfloor$ \\
\hline$d$ & Spacing of anode and cathode & $\mathrm{mm}$ & 2,4 and 8 \\
\hline$U A_{\mathrm{SSM}}$ & Unit cost of $1 \mathrm{~m}^{2}$ stainless steel mesh & $€ \cdot \mathrm{m}^{-2} \mathrm{SSM}$ & $2.90^{\mathrm{c}}$ \\
\hline
\end{tabular}

a, b, c data were estimated based on www.1688.com

COD $\mathrm{m}^{-3} \mathrm{~d}^{-1}$ ), it was still $3.8 \%$ and $7.4 \%$ higher than that for $\mathrm{R}_{\mathrm{S} 4}$ and $\mathrm{R}_{\mathrm{S} 8}$, respectively.

The above results indicated that the pollutants removal showed divergence in the three reactors with different electrode spacing under continuous flow operation. However, AO7 and COD removal efficiencies of the three reactors were presented similarly with each other under batch-fed mode operation. This suggested that the different hydrodynamics brought by electrode spacing variation at continuous flow condition had an obvious effect on the performance of BES reactor. As indicated by the larger Pe number (Table 2), the longitudinal dispersion of BES with closer electrode spacing was weakened, which may has a faster mass transfer to the surface of electrode compared with the further electrode spacing (Wang et al., 2017).Thus, faster apparent reaction rate and higher pollutants removal can be observed in $\mathrm{R}_{\mathrm{S} 2}$. Moreover, as shown in Fig. 4c, the relationships of pollutants removal with the measured HRTs were positive agreement $\left(\mathrm{R}^{2}>0.95\right)$. The correlation coefficients for AO7 and COD removals with measured HRTs based on a linear regression were both higher than 0.70 , which indicated that pollutants removal were a function of measured HRTs, and thus the measured HRT was altered by the vary of hydrodynamics of reactors. The close deployment of $f$-SSM electrode forced more of the fluid flowing through the electrode module and formed more eddies in the reactors, which indicated higher measured HRT. Therefore, the higher COD and AO7 removal of $\mathrm{R}_{\mathrm{S} 2}$ compared to $\mathrm{R}_{\mathrm{S} 4}$ and $\mathrm{R}_{\mathrm{S} 8}$ were due to prolonged the mean residence time of wastewater in $R_{S 2}$ and favorable for mass transfer.

\subsubsection{Bio-electrochemical behavior}

Under continuous flow operation, inconsistent current and columbic efficiency were observed for the three BESs with different electrode spacing (Fig. 5). $R_{S 2}$ observed the highest current and columbic efficiency of the three BESs, the current of $R_{\mathrm{S} 2}$ was higher than that of $\mathrm{R}_{\mathrm{S} 4}$ and $R_{S 8}$, which were $15.85 \pm 0.51,13.18 \pm 0.38,11.43 \pm 0.57$ and $10.82 \pm 0.46 \mathrm{~mA}$ at theoretical HRT of $2 \mathrm{~h}, 4 \mathrm{~h}, 6 \mathrm{~h}$ and $8 \mathrm{~h}$, respectively. Correspondingly, the columbic efficiencies based on AO7 and COD removal of $\mathrm{R}_{\mathrm{S} 2}$ were also the highest at different HRTs (Fig. 5b). This phenomenon was in contrast to the batch-fed mode (similar current and columbic efficiency were obtained in different reactors), indicating that the hydrodynamics companied with continuous flow operation also had a strong relationship with the bio-electrochemical performance of BESs. Fig. 5c illustrated that the current generation was generally good agreement $\left(R^{2}>0.95\right)$ with pollutants removal rate. As previous analysis, smaller electrode spacing led to longer measured HRTs and further resulted in higher pollutants removal rate at the same theoretical HRTs. Thus, the current generation was altered by the hydrodynamics characteristics that directly depend on the electrode spacing.

\subsection{Outlook and potential}

BES with close electrode spacing will increase pollutants removal performance, but that design would have more electrode surface area per volume of BES means higher capital cost. Therefore, a technoeconomic analysis that takes both of the pollutant (AO7) removal performance and the material cost into account to solve the tradeoff in BES design. The techno-economic assessment (Table 3) was based on the principle that BESs are fed by the same amount of AO7 per day and have to achieve the same $\mathrm{RE}_{\mathrm{AO} 7}$ to discharge; the scale of different $\mathrm{BES}_{f}$ SSM (including the electrode module and the reactor) can be different because of their varied $\mathrm{RR}_{\mathrm{AO} 7}$. Results demonstrated that the cost for initial capital was positively correlate to the target AO7 REs and closer electrode spacing of electrode built-in BES with lower initial cost to removal the same amount of pollutants form wastewater at all the target AO7 REs. $\mathrm{R}_{\mathrm{S} 2}$ with the minimum unit initial capital costs of the three BESs.

As expected, the $f$-SSM electrode applied for wastewater treatment may lead to plugging as biofilm growth, in the case of the wastewater, particle capture and clogging (Ahn and Schröder, 2014; Cheng et al., 2006). This study was focused on demonstrating the relationship between hydrodynamics, internal resistance and BESs pollutants removal performance resulting from electrode spacing. To explore the potential problems with electrode clogging will need long-term operation and we did not systematic exploration in this study. However, it should be noted that during the whole experiment (more than 120 days operation) of the three BESs, the electrode did not clog even with the closest electrode spacing $(2 \mathrm{~mm})$. There were several possible reasons for the failure of the cloth to clog in the BESs. The biofilms produced in electrode were much thinner compared with the electrode spacing, and the activity of biofilm proportion to the distant from the electrode surface prohibited the biofilm excessive proliferation. These $f$-SSM electrodes would be built-in liquid phase for higher performance may be porosities to help mitigate the potential for plugging in electrode (Cui et al., 2016b).

\section{Conclusion}

This study investigated the effect of electrode spacing on BES performance and clearly revealed that decreasing the electrode spacing resulted in variation of internal resistances and hydrodynamics, which further improved AO7 and COD removal during continuous flow mode. The AO7 and COD removal efficiencies in BESs with electrode spacing of $2 \mathrm{~mm}$ were $30.7 \%$ and $15.2 \%$ higher than those in BES with electrode spacing of $8 \mathrm{~mm}$, respectively. The pollutants removal varying with electrode spacing should be more ascribed to the variation of hydrodynamics. These results demonstrate that electrode spacing should be considered when BES was scaled-up. 


\section{Acknowledgements}

We gratefully acknowledge the financial support by the Natural Science Foundation of China (Grant No. 51508551, No. 21577162), the China Postdoctoral Science Foundation (Grant No. 2016T90142, No. 2015M580140), the Ministry of Environmental Protection of the People's Republic of China (Major Science and Technology Program for Water Pollution Control and Treatment, No. 2014ZX07204-005) and the Key Project of Chinese Academy of Sciences (No. ZDRW-ZS-2016$5)$.

\section{References}

Ahn, Y., Logan, B.E., 2013. Domestic wastewater treatment using multi-electrode continuous flow MFCs with a separator electrode assembly design. Appl. Microbiol. Biotechnol. 97 (1), 409-416.

Ahn, Y., Logan, B.E., 2012. A multi-electrode continuous flow microbial fuel cell with separator electrode assembly design. Appl. Microbiol. Biotechnol. 93 (5), 2241-2248.

Ahn, Y., Schröder, U., 2014. Microfabricated, continuous-flow, microbial three-electrode cell for potential toxicity detection. BioChip J. 9 (1), 27-34.

Rhines, B.P., Holland, R.W., 1979. A theoretical discussion of eddy-driven mean flows. Dyn. Atmos. Oceans 3 (2-4), 289-325.

Baudler, A., Schmidt, I., Langner, M., Greiner, A., Schröder, U., 2015. Does it have to be carbon? Metal anodes in microbial fuel cells and related bioelectrochemical systems. Energy Environ. Sci. 8 (7), 2048-2055.

Cheng, S., Liu, H., Logan, B.E., 2006. Increased power generation in a continuous flow MFC with advective flow through the porous anode and reduced electrode spacing. Environ. Sci. Technol. 40 (7), 2426-2432.

Cui, D., Guo, Y.Q., Lee, H.S., Wu, W.M., Liang, B., Wang, A.J., Cheng, H.Y., 2014 Enhanced decolorization of azo dye in a small pilot-scale anaerobic baffled reactor coupled with biocatalyzed electrolysis system (ABR-BES): a design suitable for scaling-up. Bioresour. Technol. 163, 254-261.

Cui, M.H., Cui, D., Gao, L., Wang, A.J., Cheng, H.Y., 2016a. Azo dye decolorization in an up-flow bioelectrochemical reactor with domestic wastewater as a cost-effective yet highly efficient electron donor source. Water Res. 105, 520-526.

Cui, M.H., Cui, D., Lee, H.S., Liang, B., Wang, A.J., Cheng, H.Y., 2016b. Effect of electrode position on azo dye removal in an up-flow hybrid anaerobic digestion reactor with built-in bioelectrochemical system. Sci. Rep. 6, 25223.

dos Santos, A.B., Traverse, J., Cervantes, F.J., van Lier, J.B., 2005. Enhancing the electron transfer capacity and subsequent color removal in bioreactors by applying thermophilic anaerobic treatment and redox mediators. Biotechnol. Bioeng. 89 (1), 42-52.

Escapa, A., Mateos, R., Martínez, E.J., Blanes, J., 2016. Microbial electrolysis cells: an emerging technology for wastewater treatment and energy recovery. From laboratory to pilot plant and beyond. Renew. Sustain. Energy Rev. 55, 942-956.

Escapa, A., San-Martin, M.I., Mateos, R., Moran, A., 2015. Scaling-up of membraneless microbial electrolysis cells (MECs) for domestic wastewater treatment: bottlenecks and limitations. Bioresour. Technol. 180, 72-78.

Fan, Y., Sharbrough, E., Liu, H., 2008. Quantification of the internal resistance distribution of microbial fuel cells. Environ. Sci. Technol. 42, 8101.

Ghangrekar, M.M., Shinde, V.B., 2007. Performance of membrane-less microbial fuel cell treating wastewater and effect of electrode distance and area on electricity production. Bioresour. Technol. 98 (15), 2879-2885.

Guo, K., Prevoteau, A., Patil, S.A., Rabaey, K., 2015. Engineering electrodes for microbial electrocatalysis. Curr. Opin. Biotechnol. 33, 149-156.

Heidrich, E.S., Dolfing, J., Scott, K., Edwards, S.R., Jones, C., Curtis, T.P., 2013. Production of hydrogen from domestic wastewater in a pilot-scale microbial electrolysis cell. Appl. Microbiol. Biotechnol. 97 (15), 6979-6989.

Ji, Q., Yu, D., Zhang, G., Lan, H., Liu, H., Qu, J., 2015. Microfluidic flow through polyaniline supported by lamellar-structured graphene for mass-transfer-enhanced electrocatalytic reduction of hexavalent chromium. Environ. Sci. Technol. 49 (22) 13534-13541.

Kim, K.Y., Yang, W., Logan, B.E., 2015. Impact of electrode configurations on retention time and domestic wastewater treatment efficiency using microbial fuel cells. Water Res. 80, 41-46.

Kjellstrand, R., Mattsson, A., Niklasson, C., Taherzadeh, M.J., 2005. Short circuiting in a denitrifying activated sludge tank. Water Sci. Technol. 52 (10-11), 79-87.

kumar, G.G., Sarathi, V.G., Nahm, K.S., 2013. Recent advances and challenges in the anode architecture and their modifications for the applications of microbial fuel cells. Biosens. Bioelectron 43, 461-475.

Liang, B., Cheng, H., Van Nostrand, J.D., Ma, J., Yu, H., Kong, D., Liu, W., Ren, N., Wu, L., Wang, A., Lee, D.J., Zhou, J., 2014. Microbial community structure and function of nitrobenzene reduction biocathode in response to carbon source switchover. Water Res. 54, 137-148.

Liang, B., Cheng, H.Y., Kong, D.Y., Gao, S.H., Sun, F., Cui, D., Kong, F.Y., Zhou, A.J., Liu, W.Z., Ren, N.Q., Wu, W.M., Wang, A.J., Lee, D.J., 2013. Accelerated reduction of chlorinated nitroaromatic antibiotic chloramphenicol by biocathode. Environ. Sci. Technol. 47 (10), 5353-5361.

Liu, H., Cheng, S., Logan, B.E., 2005. Power generation in fed-batch microbial fuel cells as a function of ionic strength, temperature, and reactor configuration. Environ. Sci. Technol. 39 (14), 5488-5493.

Logan, B.E., 2008. Microbial Fuel Cell, 1st ed. John Wiley \& Sons Inc, Hoboken.

Logan, B.E., Hamelers, B., Rozendal, R., Schröder, U., Keller, J., Freguia, S., Aelterman, P., Verstraete, W., Rabaey, K., 2006a. Microbial fuel cells: methodology and technology. Environ. Sci. Technol. 40, 5181-5192.

Logan, B.E., Hamelers, B., Rozendal, R., Schröder, U., Keller, J., Freguia, S.a., Aelterman, P., Rabaey, W.V.a.K., 2006b. Microbial fuel cells-methodology and technology. Environ. Sci. Technol. 40 (17), 5181-5192.

Mu, Y., Rabaey, Korneel, Rozendal, Rene A., Yuan, Zhiguo, Keller, Jurg, 2009. Decolorization of azo dyes in bioelectrochemical process. Environ. Sci. Technol. 43 (13), 5137-5143.

Munoz, P., Drizo, A., Cully Hession, W., 2006. Flow patterns of dairy wastewater constructed wetlands in a cold climate. Water Res. 40 (17), 3209-3218.

Nere, N.K., Patwardhan, A.W., Joshi, J.B., 2003. Liquid-phase mixing in stirred vessels: turbulent flow regime. Ind. Eng. Chem. Res. 42 (12), 2661-2698.

Nwabueze, T.U., Iwe, M.O., 2008. Residence time distribution (RTD) in a single screw extrusion of African breadfruit mixtures. Food Bioprocess. Technol. 3 (1), 135-145.

Pandey, A., Singh, P., Iyengar, L., 2007. Bacterial decolorization and degradation of azo dyes. Int. Biodeterior. Biodegr. 59 (2), 73-84.

Moore, Rebecca, Quarmby, J., Stephenson, Tom, 2001. The effects of media size on the performance of biological aerated filters. Water Res. 35 (10), 2514-2522.

Rozendal, R.A., Hamelers, H.V., Rabaey, K., Keller, J., Buisman, C.J., 2008. Towards practical implementation of bioelectrochemical wastewater treatment. Trends Biotechnol. 26 (8), 450-459.

Sun, J., Bi, Z., Hou, B., Cao, Y.Q., Hu, Y.Y., 2011. Further treatment of decolorization liquid of azo dye coupled with increased power production using microbial fuel cell equipped with an aerobic biocathode. Water Res. 45 (1), 283-291.

TravinM, A., StreletsP, S., Spalart, R., 2002. Physical and numerical upgrades in the detached-Eddy simulation of complex turbulent flows. Adv. LES Complex Flows 65, 239-254.

van der Zee, F.P., Villaverde, S., 2005. Combined anaerobic-aerobic treatment of azo dyes-a short review of bioreactor studies. Water Res. 39 (8), 1425-1440.

Wang, A.-J., Cheng, H.-Y., Liang, B., Ren, N.-Q., Cui, D., Lin, N., Kim, B.H., Rabaey, K., 2011. Efficient reduction of nitrobenzene to aniline with a biocatalyzed cathode environ. Sci. Technol. 45 (23), 10186-10193.

Wang, H.C., Cheng, H.Y., Cui, D., Zhang, B., Wang, S.S., Han, J.L., Su, S.G., Chen, R., Wang, A.J., 2017. Corrugated stainless-steel mesh as a simple engineerable electrode module in bio-electrochemical system: hydrodynamics and the effects on decolor ization performance. J. Hazard. Mater. 338, 287-295.

Wang, Y.Z., Wang, Y.K., He, C.S., Yang, H.Y., Sheng, G.P., Shen, J.Y., Mu, Y., Yu, H.Q., 2015. Hydrodynamics of an electrochemical membrane bioreactor. Sci. Rep. 5, 10387.

Wei, J., Liang, P., Huang, X., 2011. Recent progress in electrodes for microbial fuel cells. Bioresour. Technol. 102 (20), 9335-9344.

Zhang, B., Wen, Z., Ci, S., Chen, J., He, Z., 2014. Nitrogen-doped activated carbon as a metal free catalyst for hydrogen production in microbial electrolysis cells. RSC Adv. 4 (90), 49161-49164.

Zhang, X., Cheng, S., Wang, X., Huang, X., Logan, B.E., 2009. Separator characteristics for increasing performance of microbial fuel cells. Environ. Sci. Technol. 43 (21), 8456-8461.

Zheng, S., Yang, F., Chen, S., Liu, L., Xiong, Q., Yu, T., Zhao, F., Schröder, U., Hou, H., 2015. Binder-free carbon black/stainless steel mesh composite electrode for highperformance anode in microbial fuel cells. J. Power Sources 284, 252-257.

Zhou, M., Chi, M., Luo, J., He, H., Jin, T., 2011. An overview of electrode materials in microbial fuel cells. J. Power Sources 196 (10), 4427-4435. 